\title{
Pattern of adverse drug reactions reported at a tertiary care teaching hospital in Punjab
}

\author{
Vaishalee Punj ${ }^{1}$, Rahat Kumar ${ }^{2}$ \\ ${ }^{1}$ Department of Pharmacology, Punjab Institute of Medical Sciences, Jalandhar, Punjab, India \\ ${ }^{2}$ Department of Pharmacology, Sri Guru Ram Das Institute of Medical Sciences and Research, Amritsar, Punjab, India
}

Received: 29 October 2019

Revised: 10 December 2019

Accepted: 11 December 2019

*Correspondence:

Dr. Vaishalee Punj,

Email: shalupunj22@gmail.com

Copyright: $\odot$ the author(s), publisher and licensee Medip Academy. This is an open-access article distributed under the terms of the Creative Commons Attribution Non-Commercial License, which permits unrestricted non-commercial use, distribution, and reproduction in any medium, provided the original work is properly cited.

\begin{abstract}
Background: This study was undertaken to characterize the pattern of adverse drug reactions (ADRs) reported through spontaneous reporting system at ADR reporting unit in a tertiary care teaching hospital (Sri Guru Ram Das Institute of Medical Sciences and Research, Amritsar).

Methods: A prospective, observational study was conducted over one year between 1st July, 2013 and 30th June, 2014. The ADRs reported were from patients attending outpatient department (OPD) and in-patient department (IPD) of this hospital. Evaluation of the data was done for various parameters which included patient demographics, drug and ADR characteristics and outcome of the ADRs. Causality and severity assessment was done by WHO-UMC system and modified Hartwig and Siegel criteria.

Results: A total of 202 ADRs which were reported over one year were evaluated. Overall ADRs were more common in females than in males (60.2\% vs. $39.8 \%$ ). Majority of the ADRs were reported from psychiatry department (50\%). Most ADRs occurred due to antidepressant drugs (55.1\%). Majority of the ADRs involved the central nervous system (25.24\%). Upon causality and severity assessment, majority of the reports were rated as probable (57.42\%) and mild (57.92\%). None of the ADRs were severe or fatal.

Conclusions: In conclusion, majority of the ADRs were reported by psychiatry department and occurred due to antidepressant drugs. Most of the ADRs were mild. This data reveals the need for regular spontaneous reporting by healthcare professionals of all specialties. This data also reveals the opportunities for interventions and policy initiatives to ensure safer use of drugs in future.
\end{abstract}

Keywords: Adverse drug reactions, ADR reporting, ADR outcomes

\section{INTRODUCTION}

Adverse drug reaction (ADR) is defined by World Health Organisation as a response to a drug which is noxious and unintended, and which occurs at doses normally used in man for the prophylaxis, diagnosis, or therapy of disease, or for the modifications of physiological function. ${ }^{1}$ ADRs are an important cause of morbidity and mortality throughout World. ${ }^{2}$ A systematic review ranked ADRs among the first six causes of mortality in USA. ${ }^{2}$
ADRs are unintended and harmful consequences of medications. Once marketed medications are regularly used by patients post regulatory approval, surveillance and reporting of the ADRs becomes essential. This process of monitoring and reporting has been standardized internationally as pharmacovigilance by WHO. All national centres work jointly in the WHO Programme for Drug Monitoring, to collect reports of ADRs and send them to the Uppsala Monitoring Centre for entry into the WHO database. ${ }^{3}$ UMC continually 
monitor and analyze the VigiBase for possible signals and alerts for previously unrecognised ADRs. WHO database is also a prime resource for the study of questions on the safety of medicines.

ADR profiles differ from country to country owing to differences in genetics, traditions of populations, public health needs and medical practices. ${ }^{4}$ Increasing public expectation of safe medicines drives the need for improving the safe use of medicinal products. A national pharmacovigilance centre needs to work together with other parties including the local drug regulatory authority, health professionals, academia, governments, pharmaceutical industry and consumers.

The cost for treating a single ADR in India and US is INR 690 and US \$2500 respectively. ${ }^{5,6}$ Many factors play a crucial role in the occurrence of ADRs, including age, gender, race, pregnancy, breast feeding, kidney problems, liver function, and many other factors. These factors enable medical practitioners to choose the best drug, dose and frequency of drug regimen. ${ }^{7}$

With this in background, the aim of our study was to characterize the pattern of ADRs reported through spontaneous reporting system at ADR reporting unit in a tertiary care teaching hospital (Sri Guru Ram Das Institute of Medical Sciences and Research, Amritsar).

\section{METHODS}

A prospective, observational study was conducted over one year between 1st July, 2013 to 30th June, 2014. The ADRs reported were from patients attending out-patient department (OPD) and in-patient department (IPD) of Sri Guru Ram Das Institute of Medical Sciences and Research, Amritsar, India.

ADR data was collected in suspected ADR reporting form by Central Drugs Standard Control Organization (CDSCO), India from various departments. Analysis of data was done for ADRs collected by ADR monitoring centre of the teaching hospital for purpose of submission to Pharmacopoeia Commission (IPC), Ghaziabad that is functioning as a National Coordination Centre (NCC) for Pharmacovigilance Programme of India (PvPI). Evaluation of the data was done for various parameters which included patient demographics, drug and ADR characteristics and outcome of the ADRs.

Causality assessment was done by WHO-UMC system. ${ }^{8}$ Severity assessment was done by modified Hartwig and Siegel scale. ${ }^{9}$

\section{RESULTS}

A total of 202 ADRs were collected from various departments of Sri Guru Ram Das Institute of Medical Sciences and Research, Amritsar during the study period (1st July, 2013 to 30th June, 2014). Total number of
ADRs reported was more in females $(60 \%)$ than in males (40\%). The percentage of ADR was highest in the age group 19-60 years $(88 \%)$ followed by more than 60 years $(8.5 \%)$ and age less than 19 years $(3.5 \%)$ respectively as depicted in Table 1.

Table 1: Patient demographics.

\begin{tabular}{|ll|}
\hline Patient demographics & \\
\hline Total number of ADRs reported & 202 \\
\hline \multirow{2}{*}{ Gender-wise distribution } & Females $(60 \%)$ \\
\cline { 2 - 2 } & Males $(40 \%)$ \\
\hline \multirow{3}{*}{ Age-wise distribution (in years) } & $<19(3.5 \%)$ \\
\cline { 2 - 2 } & $19-60(88 \%)$ \\
\hline
\end{tabular}

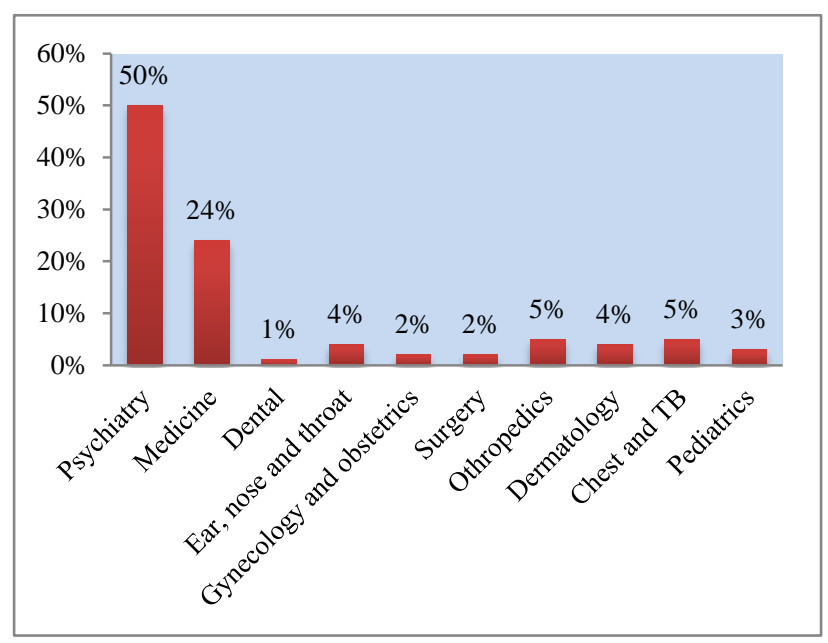

Figure 1: Department-wise distribution of ADRs.

Maximum number of ADRs were reported from psychiatry department $(50 \%)$ followed by medicine department $(24 \%)$ orthopaedics department $(5 \%)$ and chest and TB department (5\%) as shown in the Figure 1.

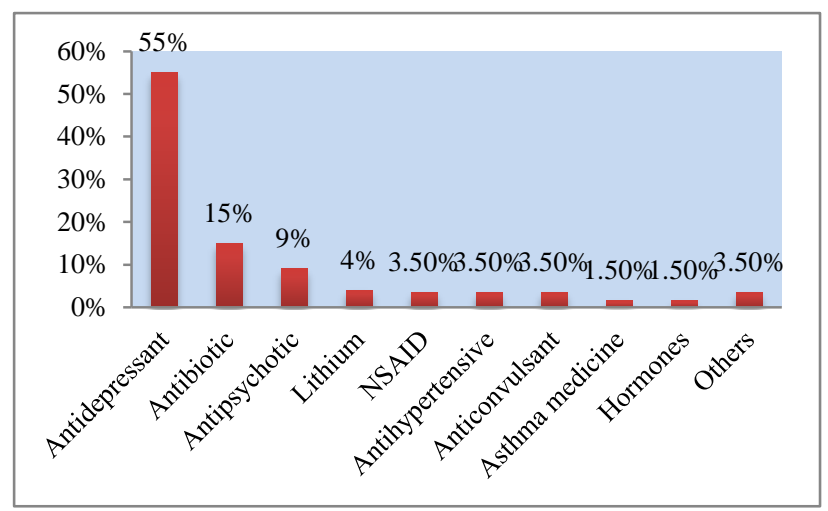

Figure 2: Distribution of ADRs among different classes of medicines.

ADRs among different class were highest for antidepressant drugs (55\%) followed by antimicrobials (15\%) and antipsychotics (9\%) as shown in Figure 2. 


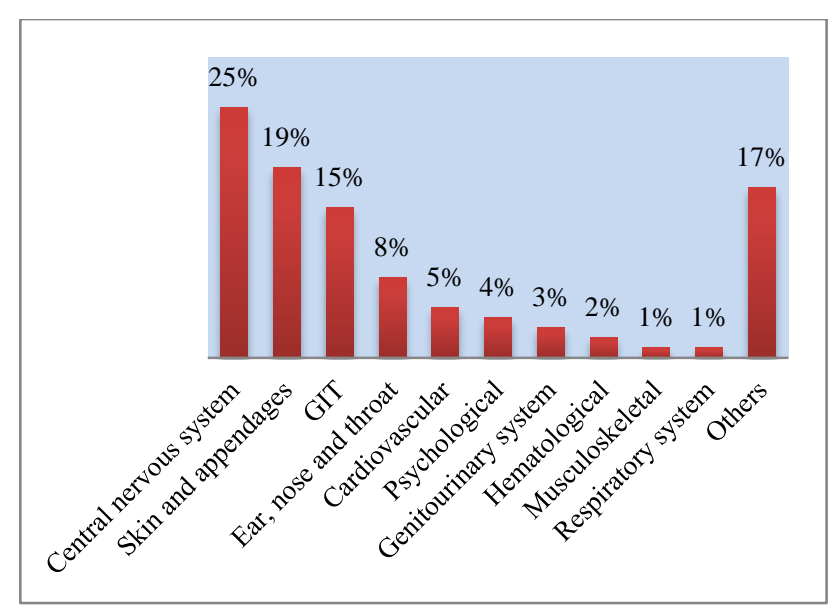

Figure 3: Organ system-wise distribution of ADRs.

The central nervous system (CNS) was found to be the most vulnerable organ, and incidence of CNS ADRs (25\%) was highest followed by skin (19\%), Gastrointestinal tract (GIT) (15\%) and ear, nose, throat (8\%) as shown in Figure 3.

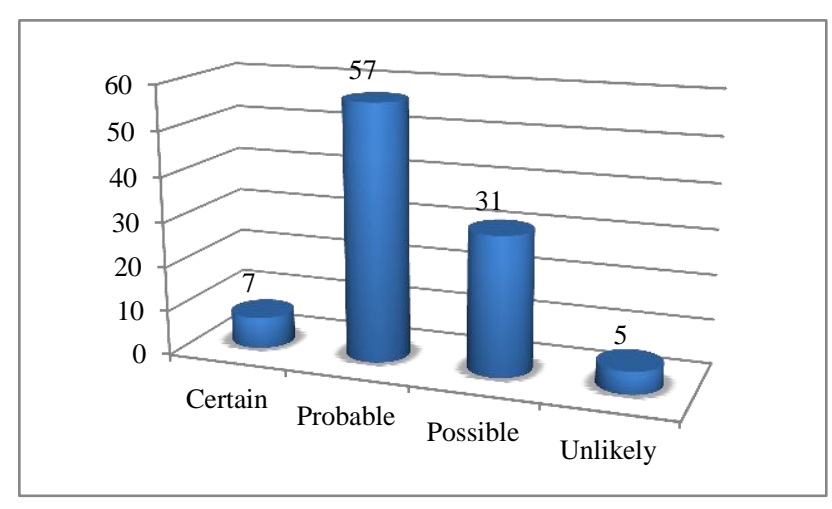

Figure 4: Causality assessment using WHO-UMC system.

According to WHO-UMC scale, causality assessment for ADRs was probable in $(57 \%)$ cases, possible in $(31 \%)$ cases, certain $(7 \%)$ and unlikely $(5 \%)$ as shown in Figure 4.

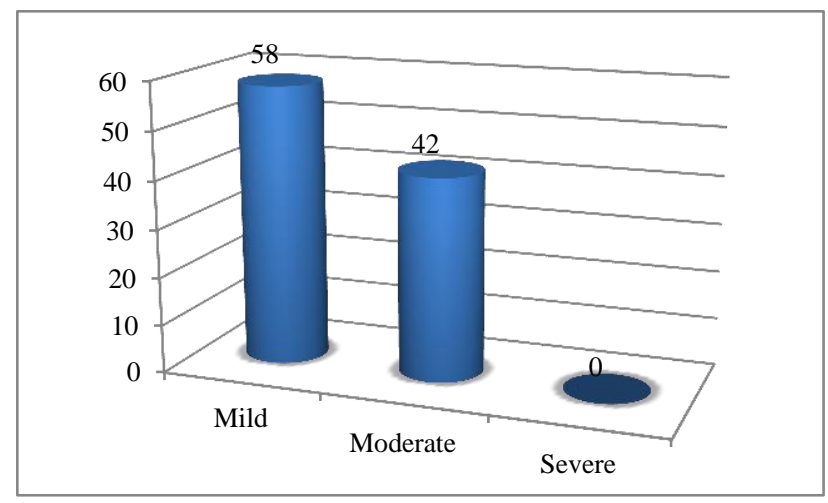

Figure 5: Severity assessment using modified Hartwig and Siegel scale.
Out of the 202 cases of ADRs encountered, (58\%) were found to be mild, $(42 \%)$ were moderate and none were of severe degree as shown in Figure 5.

\section{DISCUSSION}

This study was conducted for detection and analysis of adverse drug reactions occurring in out-patient and inpatient department of diverse disciplines of a tertiary care hospital in Amritsar, Punjab. The demographic details of the present study showed female gender predominance over males for ADRs. This gender difference has been observed in several publications worldwide and several explanations have been investigated. ${ }^{10}$ Higher reporting of ADRs in females could signify higher percentage of females accessing healthcare services. It could also reflect a higher willingness to report ADRs among females as compared to males. However, no single risk factor could be identified. ${ }^{10} \mathrm{~A}$ higher percentage of ADRs occurred in adult population (19-60 years). This corresponds roughly with female reproductive age. The pattern of demographics of ADRs reported in our hospital is comparable with the pattern of demographics reported in tertiary-care hospitals elsewhere in India. ${ }^{11,12}$

Majority of the ADRs in this hospital were reported by psychiatry department $(50 \%)$. A possible explanation could be active participation of the psychiatry department in reporting of ADRs. This finding could signify underreporting of ADRs by other departments of the hospital. More than $55 \%$ of the reported ADRs occurred due to antidepressant drugs and most ADRs involved the central nervous system $(25.24 \%)$. This finding corresponds with higher reporting by psychiatry department. This observation is similar to the study done by Jayanthi et al in which higher frequencies of ADRs were noted among patients diagnosed with depression $(34.5 \%)$ and central nervous system $(58 \%)$ was predominantly affected. ${ }^{13}$

Most of the ADRs were probable and mild. This observation is in concordance with studies conducted in India where the ADRs reported were probable and mild. ${ }^{13,14}$ In a study conducted in Italy also they observed that ADRs were expected and non-serious. ${ }^{15} 42 \%$ of ADRs were moderate however no mortality was reported. Under-reporting of severe ADRs could correspond with overall under-reporting of ADRs. It is well known that even ADR, which is considered mild or predictable in nature can have a significant impact on patient. Hence, managing and preventing all types of suspected ADRs in patients is vital.

This study revealed that there is under-reporting of ADRs by most departments in this hospital. Continued education and clarification regarding pharmacovigilance program of India can contribute to a significant increase in healthcare professionals' awareness and knowledge, hence improving patient care and outcome by optimizing drug use. 
This study also revealed the opportunities for interventions and policy initiatives to ensure safer use of drugs in future. Certain suggestions also become apparent in this study. Firstly, healthcare professionals should be aware of adverse effects of drugs at an early stage to prevent severe ADRs at a late stage. Also, reporting of severe ADRs should be made mandatory within a timeline of thirty days. Reported ADRs and case reports should be made searchable by public to help make an informed decision about a medicine.

There were some limitations of this study. First, ADR reporting was dependent on willingness of healthcare professionals. Another limitation was that survey population was limited to OPD and IPD department of single hospital and may not be representative of the rest of India. Another limitation was that most ADRs were reported by doctors while other healthcare professionals were less involved. This study was a descriptive analysis only and certain discrepancies and correlations could not be fully delineated. Lesser number of ADRs and short duration of the study were other drawbacks of this study.

\section{CONCLUSION}

Majority of adverse drug reactions in tertiary care level are preventable. Knowledge about drugs and background patient information can help to prevent easily preventable ADRs. More surveillance by ADR monitoring centre is advocated to ascertain the consistency of suspected ADRs. Regular and mandatory training of healthcare professionals on appropriate reporting of ADRs is needed to ensure reporting of ADRs thus establishing appropriate signals.

\section{ACKNOWLEDGEMENTS}

The authors gratefully acknowledge the clinical, nursing, administrative and managerial staff at the Sri Guru Ram Das Institute of Medical Sciences and Research, Amritsar, India for their assistance and support in this study.

\section{Funding: No funding sources \\ Conflict of interest: None declared \\ Ethical approval: Not required}

\section{REFERENCES}

1. WHO. Adverse reaction. WHO, 1972. Available at: http://www.who.int/medicines/areas/quality_safety/sa fety_efficacy/trainingcourses/definitions.pdf. Accessed on 3 June 2019.

2. Lazarou J, Pomeranz BH, Corey PN. Incidence of adverse drug reactions in hospitalized patients: a meta-analysis of prospective studies. JAMA. 1998;279:1200-5.

3. Lindquist M. VigiBase, the WHO Global ICSR Database System: basic facts. Drug Inf J. 2008;42(5):409-19.
4. Mazzitello C, Esposito S, De Francesco AE, Capuano A, Russo E, De Sarro G. Pharmacovigilance in Italy: an overview. J Pharmacol Pharmacother. 2013;4(1):20-8.

5. Ramesh M, Pandit J and Parthasarathi G: Adverse drug reactions in a south Indian hospital-their severity and cost involved. Pharmacoepidemiol Drug Saf. 2003;12:687-92.

6. Rabbur RSM and Emmerton L: An introduction to adverse drug reaction reporting systems in different countries. Int J Pharm Pract. 2005;13:91-100.

7. Alomar MJ. Factors affecting the development of adverse drug reactions (Review article). Saudi Pharm J. 2014;22(2):83-94.

8. The use of the WHO-UMC system for standardized case causality assessment. Available at: https://www.who.int/medicines/areas/quality_safety/s afety_efficacy/WHOcausality_assessment.pdf. Accessed on 28 October 2019.

9. Hartwig SC, Siegel J, Schneider PJ. Preventability and severity assessment in reporting adverse drug reactions. Am J Health Syst Pharm. 1992;49:222932.

10. Zopf Y, Rabe C, Neubert A, Gassmann KG, Rascher W, Hahn EG, et al. Women encounter ADRs more often than do men. Eur J Clin Pharmacol. 2008;64(10):999-1004.

11. Rehan HS, Chopra D, Sah RK, Mishra R. Adverse Drug Reactions: Trends in a Tertiary Care Hospital. Curr Drug Safety. 2012;7:384-8.

12. Shrivastava M, Uchit G, Chakravarti A, Joshi G, Mahatme M, Chaudhari H. Adverse drug reactions reported in Indira Gandhi Government Medical College and Hospital, Nagpur. J Assoc Physicians India. 2011;59:296-9.

13. Jayanthi CR, Bose D, Sushma M. Evaluation of pattern, predictability, severity and preventability of adverse drug reactions in the department of psychiatry at a tertiary care hospital in Bengaluru - a five years experience. Int $J$ Res Pharmacol Pharmacotherapeutics. 2017:6(2);182-90.

14. Behera SK, Rath B, Biswal SB and Mohapatra S. Pattern of adverse drug reactions in a tertiary care hospital in Western Odisha. Int J Pharm Sci Res. 2018;9(6):2471-7.

15. Parretta E, Rafaniello C, Magro L, Coggiola Pittoni A, Sportiello L, Ferrajolo C, et al. Improvement of patient adverse drug reaction reporting through a community pharmacist-based intervention in the Campania region of Italy. Expert Opin Drug Saf. 2014;13(1):21-9.

Cite this article as: Punj V, Kumar R. Pattern of adverse drug reactions reported at a tertiary care teaching hospital in Punjab. Int J Basic Clin Pharmacol 2020;9:166-9. 